\title{
Tracking of eating patterns and overweight - a follow-up study of Norwegian schoolchildren from middle childhood to early adolescence
}

\author{
Inger M Oellingrath ${ }^{1 *}$, Martin V Svendsen ${ }^{2}$ and Anne Lise Brantsæter ${ }^{3}$
}

\begin{abstract}
Background: The aim of this study was to describe eating patterns in early adolescence and to determine associations between eating patterns and overweight from middle childhood ( $4^{\text {th }}$ grade, 9 to 10 years old) to early adolescence ( $7^{\text {th }}$ grade, 12 to 13 years old).

Methods: Children were recruited from primary schools in Telemark County, Norway. Dietary data were obtained by parental report using a food frequency questionnaire. Height and weight were objectively measured, and overweight was defined using international standard cut-off points. Complete data were obtained for $9244^{\text {th }}$ grade and $6917^{\text {th }}$ children, and 427 children provided complete data at both time points. Principal component analysis was applied to identify eating patterns. We used multiple logistic regression to calculate adjusted odds ratios (OR) and 95\% confidence intervals (Cl) for being overweight.
\end{abstract}

Results: The same four distinct eating patterns were identified at both time points. Correlation coefficients for the factor scores of corresponding eating patterns at baseline and follow up ranged from 0.44 to 0.60 . In the follow-up sample, 345 children (80\%) were still of normal weight, while 41 (10\%) remained overweight. Children with high "dieting" pattern scores and low "varied Norwegian" pattern scores in the $7^{\text {th }}$ grade had an increased risk of being overweight. Children with stable or increased "varied Norwegian" pattern scores had a lower risk of remaining overweight over time than children with decreased scores for this pattern; adjusted OR: 0.4 (95\% Cl: 0.2, 0.8). This pattern included foods and meals close to current dietary guidelines, including vegetables, fruit and unrefined cereal products. We did not observe an increased risk of overweight in children with high "unhealthy" eating pattern scores, termed "snacking" or "junk/convenient" in either cross-sectional or longitudinal analyses.

Conclusions: Slight to moderate stability of eating patterns was observed. Children adhering to a "varied Norwegian" eating pattern were less likely to remain overweight than children with declining adherence to this pattern. Overweight children should be encouraged to eat regular main meals and retain a diverse diet that includes unrefined plant foods, water and fish, rather than fat- and sugar-reduced foods and drinks.

Keywords: tracking, dietary behaviour, eating patterns, principal component analysis, overweight, schoolchildren

\section{Background}

The construction of dietary patterns is an alternative to the use of single nutrients or food items in studies of children's food intake. Country-specific dietary patterns have recently been identified for children and adolescents in several European countries [1-9]. The dietary pattern

\footnotetext{
* Correspondence: Inger.M.Oellingrath@hit.no

${ }^{1}$ Faculty of Health and Social Sciences, Department of Health Studies,

Telemark University College, Porsgrunn, Norway

Full list of author information is available at the end of the article
}

approach may illuminate diet-disease associations that are not revealed when single nutrients or food items are used alone $[10,11]$. Dietary patterns can also be helpful in evaluating adherence to certain diets over time and risk of disease [11]. The most commonly used method for dietary pattern identification is principal component analysis (PCA), which constructs new linear factors by grouping together correlated variables [12].

In epidemiology, tracking is defined as the stability or maintenance of a given variable over time [13].

\section{Ciomed Central}


Accordingly, dietary tracking may be regarded as maintenance of nutrient intakes, food consumption or dietary habits over a certain time period [4]. Food intake and dietary habits normally change during childhood and adolescence due to individual factors like physiological development, changes in parental influence and social and environmental changes [14]. Dietary habits have mainly been tracked in adults or between adolescence and adulthood, while few studies have tracked diet during childhood [15] and from childhood to adolescence $[4,6,14,16,17]$

It has been difficult to demonstrate a consistent relationship between BMI in children and dietary factors like fat intake or total energy intake in cross-sectional studies and longitudinal observation studies [18-20]. While most cross-sectional studies have found negative associations between energy-rich foods and overweight, some longitudinal studies have reported a positive association between weight gain over time and consumption of high-fat foods and sugar-sweetened drinks [21,22]. A comprehensive review of studies examining the relationship between dietary intakes, eating behaviours and childhood obesity concluded that more research is needed, particularly in the form of studies exploring the joint effect of multiple dietary behaviours [23]. Two recently published studies have documented a positive relationship between energydense diets and overweight in children [24,25]. Further longitudinal studies exploring the association between complex diets and overweight in children are needed.

We have previously reported the association between PCA-identified eating patterns and overweight in a crosssectional study in 9- to 10-year-old children in Telemark County, Norway [3]. The present study is a follow-up of the same children three years later, in early adolescence ( $7^{\text {th }}$ grade, 12 to 13 years of age). The aim of the study was to a) describe eating patterns in early adolescence and b) to determine the association between eating patterns and overweight from middle childhood to early adolescence.

\section{Methods}

\section{Subjects and study design}

The present data were obtained from a study of primary school pupils in Telemark County, Norway. Data collection took place in the spring of 2007 and spring of 2010, when the children were in primary school grades 4 ( 9 to 10 year old) and 7 (12 to 13 years old) respectively. The detailed methods for the $4^{\text {th }}$ grade data collection have been described previously [3]. An identical procedure was used for data collection in the $7^{\text {th }}$ grade. In brief, all primary schools in Telemark County were invited to participate in the study at both time points. Of 110 invited schools 70 agreed to participate in the $4^{\text {th }}$ grade data collection and 53 of 104 participated in the $7^{\text {th }}$ grade data collection. In total, written parental consent to inclusion in the study was received for 1,045 out of 1,477 invited children in the $4^{\text {th }}$ grade and 1,095 out of 1,503 invited children in the $7^{\text {th }}$ grade. This represented about half of the county's $4^{\text {th }}$ and $7^{\text {th }}$ grade pupils at the respective time points.

Weight and height measurements were obtained for 955 $\left(4^{\text {th }}\right.$ grade) and 865 ( $7^{\text {th }}$ grade) children, while complete weight/height and dietary data were obtained for 924 and 691 pupils, respectively. In total, 427 children provided complete weight, height and dietary data at both time points (Figure 1).

The research protocol was approved by the Regional Committee for Ethics in Medical Research and the Norwegian Data Inspectorate. Informed written consent was obtained from the parents of all participating children in both 2007 and 2010.

\section{Dietary information}

The children's food and drink intake was reported by their parents using a retrospective food frequency questionnaire (FFQ), which asked about habitual daily consumption of 40 food items, 11 types of drink, 13 types of snacks (between meals) and five main meals (breakfast, lunch, afternoon meal, dinner, supper) during the last six months. Identical FFQs were used at both time points. This questionnaire was based on a short FFQ developed for use among fourthand eighth-grade children in Norway, but was modified to include more dietary questions. The modified FFQ is appropriate for exploring dietary patterns based on frequencies, but has not been validated for estimating total intakes of energy or nutrients. The alternative frequencies for food and drink items were: "rarely/never", "1-3 times a month", "1-3 times a week", "4-6 times a week", "once a day", "twice a day", and " 3 or more times per day". Meal patterns were registered as the daily frequencies of five main meals (breakfast, lunch, afternoon meal, dinner, supper), with 8 response alternatives ranging from "never/ rarely" to "daily". The questions about snacking between meals had three answer categories: "never/rarely", "sometimes" and "often/always". As we used meal and snacking events in addition to food consumption frequencies as input variables in the PCA, the components were denoted as 'eating patterns' rather than 'dietary patterns'.

\section{Other variables}

In addition to providing dietary information, the parents answered questions about their own weight, height, educational level and work situation, and family income. They also provided their subjective opinion regarding their child's physical activity level compared with that of other children of the same age, and of time spent on screenbased activities and other sedentary activities outside school (e.g. reading or homework). 


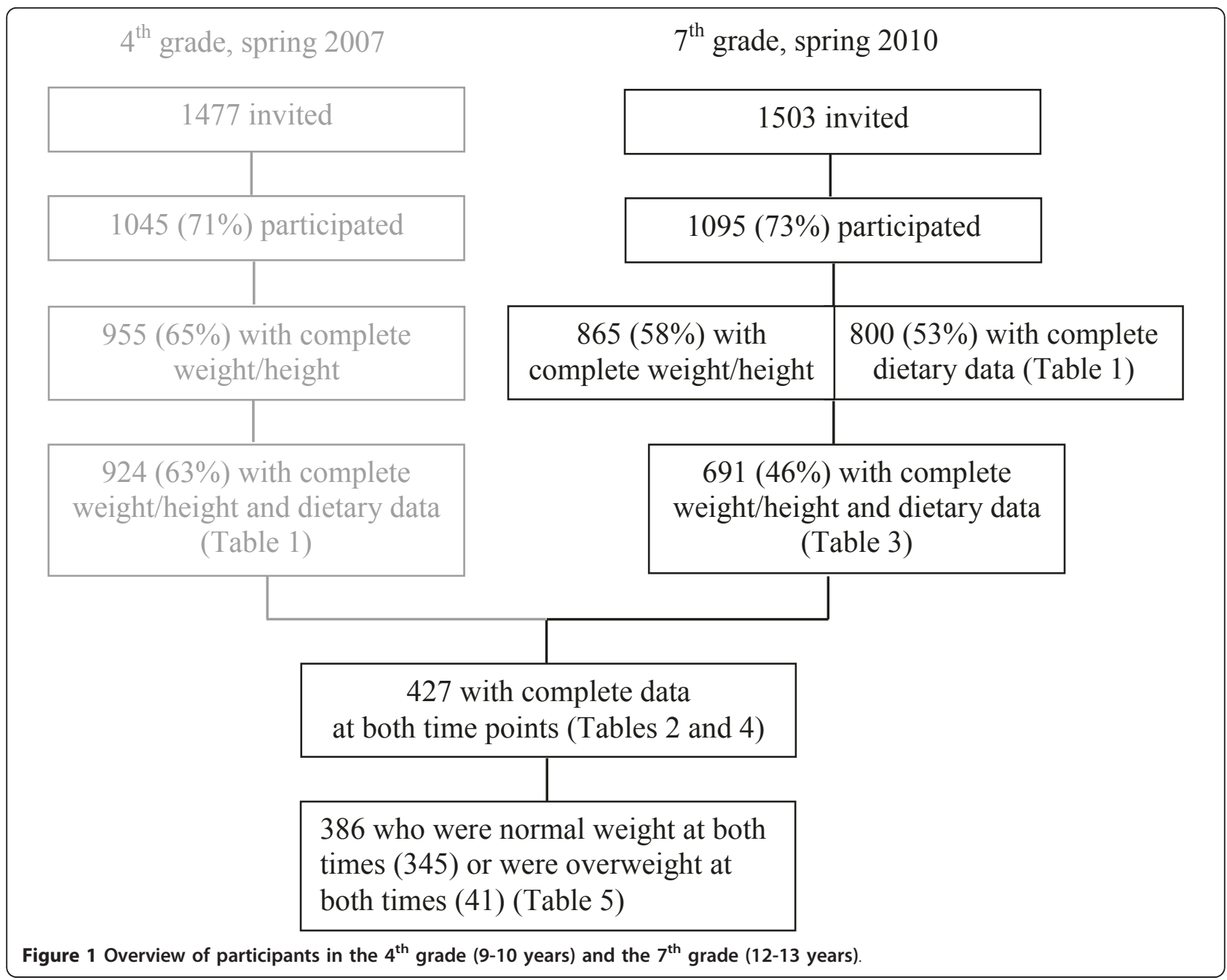

Parental educational level was divided into three categories: "primary and lower secondary education" (10 years or less), "upper secondary education" (three to four years of secondary education), and "university or university college".

Family income was divided into three categories: "both parents < Norwegian kroner (NOK) 300,000 (EUR $33,909)$ ", "one parent $\geq$ NOK 300,000", and "both parents $\geq$ NOK 300,000 ".

A variable categorising leisure physical activity by reference to other children was used as an indicator of the children's physical activity level. Parents indicated on a scale from 1-5 whether the child was "less physically active than other children of the same age" or "more physically active compared to other children of same age". The question was taken from a battery of validated questions used in a study of children's activity and inactivity in the Netherlands [26], and translated into Norwegian for use in the present study.
Inactivity was defined as time spent on screen-based activities and other sedentary activities outside school. These activities were combined and divided into two categories: "less than 4 hours per day", and " 4 hours or more per day".

\section{BMI categories}

The weight and height of the children were measured by public health nurses at each school at both time points. The children were weighed wearing light clothing (i.e. trousers, T-shirt, socks), using calibrated, electronic scales measuring in $100 \mathrm{~g}$ increments. BMI $\left(\mathrm{kg} / \mathrm{m}^{2}\right)$ of each child was calculated on the basis of these measurements. Child BMI categories were calculated using International Obesity Task Force (IOTF) cut-off points (underweight, normal weight, overweight, obese), based on growth curves and BMIs of 17, 25 and $30 \mathrm{~kg} / \mathrm{m}^{2}$ at age 18 years $[27,28]$. The respective cut-off points for 9.5-year-old and 12.5year-old boys and girls were used. Due to small numbers 
we included underweight children in the normal weight group and obese children in the overweight group.

Changes in BMI categories between the $4^{\text {th }}$ grade and the $7^{\text {th }}$ grade were divided into four categories: "unchanged normal weight", "overweight to normal weight", "normal weight to overweight", and "unchanged overweight". Parent BMI categories were calculated on the basis of self-reported height and weight and the IOTF cutoff points for adults (overweight at $\mathrm{BMI} \geq 25 \mathrm{~kg} / \mathrm{m}^{2}$ ).

\section{Statistical analyses}

At each of the two time points, we used PCA with varimax rotation to identify eating patterns from the reported dietary responses [29]. Food and drink frequencies were assigned values from 1 for "never/rarely" to 7 for "3 or more times daily", while meal frequencies were assigned values from 1 for "rarely/never" to 8 for "daily" and snacking between meals were assigned 1 for "never/rarely", 2 for "sometimes" and 3 for "often/always". Missing values for a given variable were replaced by rarely/never. Respondents were excluded from the analysis if answers were missing for $16(23 \%)$ or more of the questions about food and drink items or if answers were missing for more than two questions $(40 \%)$ about meals $(n=31$ and $n=68$ for the $4^{\text {th }}$ grade and the $7^{\text {th }}$ grade, respectively).

PCA constructs new linear factors by grouping together correlated variables. The coefficients defining the factors are called factors loadings and represent the correlations of each input variable with the factors. The number of components chosen from the factor analysis was based on the scree plot, eigenvalues and the interpretability of the components [29]. The criteria for choosing the components were identical at both time points. Variables with factor loadings $>0.25$ or $<-0.25$ were considered important for interpretability of the components. The components (called eating patterns) were named after the nature of the foods, beverages and meals with the highest factor loadings within each pattern. The four eating patterns previously identified for the children in the $4^{\text {th }}$ grade [3] were: a "snacking" pattern, characterised by snack items and sugar-sweetened drinks, low intake of water, vegetables and brown bread and a low frequency of eating breakfast and dinner; a pattern labelled "junk/convenient", characterised by high-fat and high-sugar processed fast foods; a "varied Norwegian" pattern, characterised by food items typical of a traditional Norwegian diet, close to what is recommended by the health authorities; and, finally, a "dieting" pattern, containing foods and drinks often associated with dieting and weight control.

Individuals were given factor scores for each of the patterns. Factor scores were standardised to a mean of zero. Positive factor scores indicate higher consumption of foods, drinks, snacks and meals in that pattern, while negative factor scores indicate low consumption. The factor scores for each eating pattern were used in the further analysis as continuous variables, or ranked into categorical variables (tertiles).

The factor scores were approximately normally distributed. Therefore, Pearson's correlation coefficients were used to evaluate the agreement between the factor scores for similar and different eating patterns at the two time points. Additionally, Cohen's weighted kappa $(\kappa)$ [30] was used to compare individual factor scores as categorical variables (tertiles) across time. Cohen's $\kappa$ for being in the same weight group at both time points was also calculated. In accordance with the scale of Landis and Koch [31], we interpreted the $\kappa$-values to represent the following agreement between time points: 0.01 to 0.20 : "slight"; 0.21 to 0.4: "fair"; 0.41 to 0.60 : "moderate"; 0.61 to 0.80 : "substantial"; and 0.81 to 1.00 : "almost perfect". BMI was not normally distributed, and Spearman's rho was used for correlation analysis.

Analysis of variance (ANOVA) was used to examine differences in pattern scores between groups. We used multiple logistic regression to calculate adjusted odds ratios (OR) and 95\% confidence intervals (CI) for being overweight in the $7^{\text {th }}$ grade and for staying overweight from the $4^{\text {th }}$ to the $7^{\text {th }}$ grade. Categorised pattern scores (low, medium and high, based on tertiles) and a dichotomous variable denoting increase/decrease in pattern scores were used as categorical independent variables in the models, respectively.

We used multiple linear regression and independent samples $\mathrm{T}$-test to examine the changes in eating pattern scores in relation to changes in BMI categories. Changes in eating pattern scores over time were calculated as the difference in pattern scores from the $4^{\text {th }}$ to the $7^{\text {th }}$ grade. The difference within each pattern was examined as the dependent variable, while changes in BMI categories were used as independent variables, with "unchanged normal weight" as the reference category and "overweight to normal weight", "normal weight to overweight", and "unchanged overweight" as independent dichotomous variables.

In order to examine adherence to eating patterns over time, we categorised the changes in eating pattern scores from the $4^{\text {th }}$ to the $7^{\text {th }}$ grade into dichotomous variables denoting either unchanged/increased adherence to the pattern (no change or positive change) or reduced adherence to the pattern (negative change).

The potential confounding variables in the multiple regression models were: maternal and paternal overweight, maternal and paternal education, family income, child physical activity, child sedentary activity, and child gender. We applied a forward conditional selection and included variables significantly associated with overweight in each 
model. Adjusting for all of the variables had little additional impact on the effect estimates, and led to no changes in the main conclusions in this article.

For all tests, $\mathrm{P}<0.05$ was considered significant. The questionnaires were scanned by Eyes and Hands (Readsoft Forms, Helsingborg, Sweden), and all the statistical analyses were carried out using SPSS version 15.

\section{Results}

Four distinct eating patterns were identified at both time points $\left(\mathrm{n}=924\right.$ and $\mathrm{n}=800$ for the $4^{\text {th }}$ and the $7^{\text {th }}$ grade, respectively), which were comparable over time (Table 1 ). The main composition (high-loading items) obtained in the $4^{\text {th }}$ grade was maintained for all four eating patterns in the $7^{\text {th }}$ grade (Table 1). However, some modifications due to changes of items between patterns could be observed, mainly related to items with low factor loadings (between -0.30 and +0.30$)$. A separate PCA performed on the follow-up sample $(n=427)$ showed only minor differences in eating pattern composition and respective factor loadings compared to the whole sample. The changes observed over time were mainly related to the "varied Norwegian" pattern. Meat for dinner and juice during and between meals, which were part of this pattern in the $4^{\text {th }}$ grade, did not have high loadings for the pattern in the $7^{\text {th }}$ grade, while several main meals and food items were added to the $7^{\text {th }}$-grade pattern: breakfast, lunch, rice, water, jam/ honey and margarine/butter on bread (Table 1). Furthermore, low-fat white cheese and yoghurt products, which loaded positively in the "varied Norwegian" pattern in the $4^{\text {th }}$ grade, loaded positively in the "dieting" pattern in the $7^{\text {th }}$ grade. In fact, all yoghurt products loaded positively in the "dieting" pattern in the $7^{\text {th }}$ grade. The main change in the "snacking" pattern was the addition of sugar-sweetened, carbonated soft drinks and "eating between meals" at the $7^{\text {th }}$-grade stage (Table 1). Only small changes were observed for the "junk/convenient" pattern over the time period studied (Table 1).

In the $4^{\text {th }}$ grade, the "snacking" pattern explained the largest amount of variance in the data, followed by the patterns "junk/convenient", "varied Norwegian" and "dieting". In the $7^{\text {th }}$ grade however, the "junk/convenient" pattern and the "varied Norwegian" pattern accounted for the largest variations in overall diet. The names or 'labels' that were used to describe the patterns in the $4^{\text {th }}$ grade were highly appropriate to the patterns extracted in the $7^{\text {th }}$ grade, and seemed to describe the composition of the $7^{\text {th }}$. grade patterns even better than the composition of the $4^{\text {th }}$ grade patterns. The "varied Norwegian" pattern was more prominent at the $7^{\text {th }}$-grade stage, as it explained a larger proportion of the variance in intake frequencies and included a larger variety of foods, drinks and main meals.

The Pearson's correlation coefficients for factor scores for the four corresponding eating patterns at the two time points ranged from 0.44 to 0.60 (Table 2). Additionally, the pattern scores for "snacking" and "dieting" in the $4^{\text {th }}$ grade were inversely related to "varied Norwegian" scores in the $7^{\text {th }}$ grade (Table 2). The weighted $\kappa$-values for being in the same tertile at the two time points were $0.50,0.49,0.37$, and 0.44 for the "junk/convenient", "varied Norwegian", "snacking" and "dieting" eating patterns, respectively.

At both time points, $50 \%$ of the participants were boys and $50 \%$ were girls. Weight and height were obtained for 955 (50\% boys and $50 \%$ girls) of the 1,045 participating children at the $4^{\text {th }}$-grade stage (91\%), and for $865(49 \%$ boys and $51 \%$ girls) of the 1,095 at the $7^{\text {th }}$-grade stage (79\%). For children with complete weight and height measurements at both time points $(\mathrm{n}=540)$, BMI correlated with $\mathrm{r}=0.82(95 \% \mathrm{CI}: 0.79,0.84)$. The distribution between normal weight, overweight and obesity was $80 \%$, $16 \%$ and $4 \%$ in the $4^{\text {th }}$ grade and $81 \%, 15 \%$ and $3 \%$ in the $7^{\text {th }}$ grade, respectively. While the incidences of overweight/obesity among boys and girls did not differ in the $4^{\text {th }}$ grade $(21 \%$ for boys and $20 \%$ for girls $(\mathrm{p}=0.851)$ ), a significant difference was seen in the $7^{\text {th }}$ grade $(21 \%$ for boys and $15 \%$ for girls $(\mathrm{p}=0.001)$ ).

In the follow-up sample $(\mathrm{n}=427), 345(80 \%)$ of the children were still of normal weight ( $48 \%$ boys, $52 \%$ girls), while $20(5 \%)$ changed from overweight to normal weight ( $55 \%$ boys, $45 \%$ girls), 21 (5\%) changed from normal weight to overweight (71\% boys, $29 \%$ girls) and $41(10 \%)$ remained overweight ( $49 \%$ boys, $51 \%$ girls). Cohen's Kappa for being in the same weight group at both time points was 0.61 (95\% CI: 0.50, 0.72).

At the $7^{\text {th }}$-grade stage $(n=800)$, the "varied Norwegian" pattern scores were negatively associated with maternal overweight and positively associated with physical activity and with maternal and paternal educational level. The "snacking pattern" scores were positively associated with sedentary behaviour and negatively associated with family income and maternal and paternal educational level. The dieting pattern scores were positively associated with maternal educational level and were higher for girls than boys, while the "junk/convenient" pattern scores were higher for boys than girls ( $\mathrm{p}<0.05$ for all, data not shown).

Cross-sectional analysis of dietary patterns and overweight in the $7^{\text {th }}$ grade showed the highest incidence of overweight in the lower tertile of the "varied Norwegian" pattern (23\%) and the upper tertile of the "dieting" pattern (24\%) (Table 3). The lowest incidence of overweight was observed in the upper tertile of the "varied Norwegian" pattern (12\%) and in the two lower tertiles of the "dieting" pattern (13\%). Children ranked in the upper tertile of the "varied Norwegian" pattern were less likely to be overweight than those in the lower tertiles (Table 3), in contrast to what was found in the $4^{\text {th }}$ grade, where high 
Table 1 Structure of the eating patterns extracted for the $4^{\text {th }}-(n=924)$ and $7^{\text {th }}-$ grade $(n=800) \mathrm{children}^{\S}$

\begin{tabular}{|c|c|c|c|c|c|c|c|c|}
\hline & \multicolumn{2}{|c|}{ 'Junk/convenient' } & \multicolumn{2}{|c|}{ 'Varied Norwegian' } & \multicolumn{2}{|c|}{ 'Snacking' } & \multicolumn{2}{|c|}{ 'Dieting' } \\
\hline & $\begin{array}{l}4^{\text {th }} \\
\text { grade }\end{array}$ & $\begin{array}{c}7^{\text {th }} \\
\text { grade }\end{array}$ & $\begin{array}{c}4^{\text {th }} \\
\text { grade }\end{array}$ & $\begin{array}{c}7^{\text {th }} \\
\text { grade }\end{array}$ & $\begin{array}{l}4^{\text {th }} \\
\text { grade }\end{array}$ & $\begin{array}{c}7^{\text {th }} \\
\text { grade }\end{array}$ & $\begin{array}{l}4^{\text {th }} \\
\text { grade }\end{array}$ & $\begin{array}{c}7^{\text {th }} \\
\text { grade }\end{array}$ \\
\hline Variance explained by the factor (pattern) & $6 \%$ & $8 \%$ & $4 \%$ & $6 \%$ & $7 \%$ & $4 \%$ & $3 \%$ & $3 \%$ \\
\hline French fries in fast food restaurants & 0.60 & 0.64 & & & & & & \\
\hline Hamburger or kebab & 0.56 & 0.64 & & & & & & \\
\hline French fries for dinner & 0.49 & 0.50 & & & & & & \\
\hline Biscuits, cakes, crackers, etc. & 0.51 & 0.48 & & & & & & \\
\hline Sausages, hot dog & 0.44 & 0.47 & & & & & & \\
\hline Processed pizza & 0.41 & 0.46 & & & & & & \\
\hline Waffles & 0.47 & 0.46 & & & & & & \\
\hline Sweets & 0.32 & 0.40 & & & & & & \\
\hline Salty snacks & 0.32 & 0.40 & & & & & & \\
\hline White bread & 0.34 & 0.40 & & & & & & \\
\hline Ice cream & 0.44 & 0.39 & & & & & & \\
\hline Processed meat for dinner & 0.26 & 0.30 & & & & & & \\
\hline Pancakes & 0.45 & 0.30 & & & & & & \\
\hline Fruits and berries & & & 0.53 & 0.59 & & & & \\
\hline Vegetables & & & 0.50 & 0.58 & -0.32 & & & \\
\hline Fish for dinner & & & 0.40 & 0.44 & & & & \\
\hline Water & & & & 0.44 & -0.35 & & & \\
\hline Brown bread & & & 0.30 & 0.40 & -0.28 & & & \\
\hline $\begin{array}{l}\text { Fruits, berries or } \\
\text { vegetables between meals }\end{array}$ & & & 0.44 & 0.37 & & 0.28 & & \\
\hline Processed fish for dinner & & & 0.32 & 0.37 & & & & \\
\hline White cheese, full-fat & & & 0.34 & 0.36 & & & & \\
\hline Cereals without sugar & & & 0.34 & 0.34 & & & & 0.28 \\
\hline Brown cheese, full-fat & & & 0.27 & 0.34 & & & & \\
\hline Water between meals & & & 0.28 & 0.31 & & & & \\
\hline Low-fat meat on sandwich & & & 0.35 & 0.31 & & & & \\
\hline Lunch & & & & 0.31 & & & & \\
\hline Potatoes, boiled & & & 0.27 & 0.29 & & & & \\
\hline Breakfast & & & & 0.28 & -0.31 & & & \\
\hline Jam, honey as spread & & & & 0.28 & & & & \\
\hline Fish spread & & & 0.35 & 0.27 & & & & \\
\hline Butter or margarine on bread & & & & 0.26 & & & & \\
\hline Rice & 0.25 & & & 0.25 & & & & \\
\hline Non-processed meat for dinner & & & 0.29 & & & & & \\
\hline Juice & & & 0.31 & & & & & \\
\hline Dinner & & & & & -0.28 & & & \\
\hline Pasta & & & & & -0.28 & & & \\
\hline Sugar-sweetened soft drinks, carbonated (between meals) & & & & & 0.62 & 0.59 & & \\
\hline $\begin{array}{l}\text { Sugar-sweetened soft drinks, non-carbonated (between } \\
\text { meals) }\end{array}$ & & & & & 0.60 & 0.58 & & \\
\hline Sweets between meals & & & & & 0.58 & 0.55 & & \\
\hline Juice between meals & & & 0.35 & & 0.43 & 0.52 & & 0.26 \\
\hline Biscuits, cakes, crackers, etc. between meals & 0.34 & 0.28 & & & 0.41 & 0.50 & & \\
\hline Salty snacks between meals & & 0.25 & & & 0.46 & 0.48 & & \\
\hline Ice cream between meals & 0.25 & & & & 0.43 & 0.45 & & \\
\hline Milk between meals & & & & & 0.47 & 0.43 & & \\
\hline Sugar-sweetened soft drinks, non-carbonated & & & & & 0.33 & 0.43 & -0.47 & -0.33 \\
\hline Yoghurt between meals & & & 0.41 & & 0.43 & 0.41 & & 0.36 \\
\hline Eating in between meals & & & & & & 0.35 & & \\
\hline
\end{tabular}


Table 1 Structure of the eating patterns extracted for the $4^{\text {th }}-(n=924)$ and $7^{\text {th }}$-grade $(n=800)$ children ${ }^{\text {? } ?}$ (Continued)

\begin{tabular}{|c|c|c|c|c|c|c|c|c|}
\hline Sugar-sweetened soft drinks, carbonated & 0.34 & 0.28 & & & & 0.31 & -0.36 & -0.29 \\
\hline $\begin{array}{l}\text { Artificially sweetened soft drinks, non-carbonated, } \\
\text { (between meals) }\end{array}$ & & & & -0.31 & 0.30 & & 0.66 & 0.57 \\
\hline Artificially sweetened soft drinks, carbonated & & & & & & & 0.63 & 0.56 \\
\hline Artificially sweetened soft drinks, non-carbonated & & 0.25 & & -0.29 & & & 0.65 & 0.55 \\
\hline Fat- and sugar-reduced yoghurt & & & 0.36 & & & & 0.29 & 0.50 \\
\hline $\begin{array}{l}\text { Artificially sweetened soft drinks, carbonated (between } \\
\text { meals) }\end{array}$ & & & & & 0.37 & & 0.54 & 0.47 \\
\hline White cheese, low-fat & & & 0.33 & & & & 0.26 & 0.43 \\
\hline Yoghurt with cereal & & & 0.33 & & & 0.25 & & 0.42 \\
\hline Fruit yoghurt & & & 0.45 & 0.27 & & & & 0.40 \\
\hline Cereals and breakfast mixtures containing sugar & 0.33 & & & & & & & \\
\hline Chocolate spread & 0.28 & & & & & & & \\
\hline
\end{tabular}

${ }^{\S}$ Food items, snacks and meals with factor loadings $>0.25$ or $<-0.25$ are listed. Patterns are presented by extraction order at the $7^{\text {th }}$-grade stage.

scores for the "varied Norwegian" eating pattern were associated with an increased risk of overweight [3]. Studying the association between single foods and meals and overweight at both time points showed a lower intake of vegetables and less regular breakfast eating among overweight compared to normal weight children at the $7^{\text {th }}$ grade stage.

Independently of this, children ranked in the upper tertile of the "dieting" pattern were more likely to be overweight than those in the lower tertiles in the $7^{\text {th }}$ grade. After adjustment for influential confounders in the model, the associations remained significant (Table 3). No significant associations were observed between either the "junk/convenient pattern" or the "snacking pattern" and overweight in the $7^{\text {th }}$ grade.

Multiple linear regression analysis of the relationship between changes in eating pattern scores and changes in BMI categories over time revealed no significant associations, but weak trends in the data could be observed (Table 4). Compared to children who remained within the "normal weight" category at both time points, children who changed from normal weight to overweight tended to reduce their "junk/convenient" and "snacking" patterns scores and increase their "dieting" pattern scores, while children who changed from overweight to normal weight tended to increase their "snacking" pattern scores. Furthermore, those who were overweight at both time points tended to reduce their scores for the "varied Norwegian" pattern and increase their scores for the "dieting" pattern, compared to the children who stayed normal weight between the $4^{\text {th }}$ and $7^{\text {th }}$ grade (Table 4 ).

Finally, we examined the likelihood of remaining in the overweight category over time relative to unchanged/ increased adherence to a pattern (no change or positive change in scores between the $4^{\text {th }}$ and $7^{\text {th }}$ grade), or reduced adherence to a pattern (negative change). Children with stable or increased "varied Norwegian" pattern scores showed a significantly lower risk of remaining in the overweight category, compared to children with decreased "varied Norwegian" pattern scores. The association was independent of parental characteristics and child activity/inactivity (Table 5).

\section{Discussion}

The most important finding in the present study was that children adhering to a "varied Norwegian" eating pattern over time had lower risk of remaining overweight than children with declining adherence to this pattern. Crosssectional analysis of data obtained at the $7^{\text {th }}$-grade stage evidenced a significantly lower risk of being overweight for children with high "varied Norwegian" eating pattern scores, and an increased risk of being overweight for children with high "dieting pattern" scores. Neither cross-sectional nor longitudinal data analysis results indicated an

Table 2 Correlation coefficients ${ }^{\S}$ for the corresponding eating pattern scores for $4^{\text {th }}$ - and $7^{\text {th }}$-grade children $(n=427$ )

\begin{tabular}{|c|c|c|c|c|}
\hline & 7th grade 'Snacking' & 7th grade 'Junk/convenient' & $\begin{array}{c}\text { 7th grade } \\
\text { 'Varied Norwegian' }\end{array}$ & $\begin{array}{l}\text { 7th grade } \\
\text { 'Dieting' }\end{array}$ \\
\hline & $r(95 \% \mathrm{Cl})$ & $r(95 \% \mathrm{Cl})$ & $r(95 \% \mathrm{Cl})$ & $r(95 \% \mathrm{Cl})$ \\
\hline \multicolumn{5}{|l|}{4 th grade } \\
\hline 'Snacking' & $0.44(0.36,0.51)$ & $0.01(-0.09,0.10)$ & $-0.23(-0.31,-0.13)$ & $0.06(-0.15,0.04)$ \\
\hline 'Junk/convenient' & $0.06(-0.04,0.15)$ & $0.58(0.51,0.64)$ & $-0.10(-0.19,0.00)$ & $-0.01(-0.10,0.09)$ \\
\hline 'Varied Norwegian' & $0.09(-0.00,0.18)$ & $-0.09(-0.18,0.01)$ & $0.60(0.53,0.65)$ & $0.28(0.13,0.32)$ \\
\hline 'Dieting' & $-0.16(-0.25,-0.06)$ & $0.07(-0.02,0.17)$ & $-0.31(-0.39,-0.22)$ & $0.51(0.43,0.57)$ \\
\hline
\end{tabular}

\footnotetext{
${ }_{\S}$ Pearsons correlation coefficients ( $r$ ) and 95\% confidence intervals (Cl).
} 
Table 3 Cross-sectional associations ${ }^{\S}$ between tertiles of eating pattern scores and overweight in $7^{\text {th }}$ grade $(\mathrm{n}=691)$

\begin{tabular}{|c|c|c|c|c|}
\hline Eating pattern & $\mathrm{n}$ & $\begin{array}{l}\text { Overweight and } \\
\text { obese children } \\
\mathrm{n}(\%)\end{array}$ & OR $_{\text {crude }}{ }^{1}(95 \% \mathrm{Cl})$ & OR adjusted ${ }^{2}(95 \% \mathrm{Cl})$ \\
\hline \multicolumn{5}{|l|}{ 'Junk/convenient' } \\
\hline Tertile 1 & 237 & $42(18)$ & 1 & 1 \\
\hline Tertile 2 & 230 & $38(17)$ & $1.0(0.6,1.6)$ & $1.0(0.6,1.6)$ \\
\hline Tertile 3 & 224 & $34(15)$ & $0.8(0.5,1.3)$ & $0.8(0.5,1.4)$ \\
\hline \multicolumn{5}{|c|}{ 'Varied Norwegian' } \\
\hline Tertile 1 & 222 & $50(23)$ & 1 & 1 \\
\hline Tertile 2 & 232 & $36(16)$ & $0.6(0.4,1.0)$ & $0.7(0.4,1.2)$ \\
\hline Tertile 3 & 237 & $28(12)$ & $0.5(0.3,0.8)$ & $0.6(0.4,0.9)$ \\
\hline \multicolumn{5}{|l|}{ 'Snacking' } \\
\hline Tertile 1 & 222 & $39(18)$ & 1 & 1 \\
\hline Tertile 2 & 237 & $37(16)$ & $0.8(0.5,1.3)$ & $0.9(0.5,1.5)$ \\
\hline Tertile 3 & 232 & $38(16)$ & $0.9(0.5,1.5)$ & $1.0(0.6,1.6)$ \\
\hline \multicolumn{5}{|l|}{ 'Dieting' } \\
\hline Tertile 1 & 232 & $30(13)$ & 1 & 1 \\
\hline Tertile 2 & 234 & $31(13)$ & $1.0(0.6,1.8)$ & $1.1(0.6,1.9)$ \\
\hline Tertile 3 & 225 & $53(24)$ & $2.1(1.3,3.4)$ & $2.2(1.3,3.8)$ \\
\hline
\end{tabular}

${ }^{\S}$ Odds ratios (OR) and $95 \%$ confidence intervals $(95 \% \mathrm{Cl})$.

${ }^{1}$ Adjusted for the other eating patterns.

${ }^{2}$ Adjusted for the other eating patterns and significantly associated background variables.

Table 4 Changes $^{\S}$ in eating pattern scores relative to change in BMI categories between the $4^{\text {th }}$ and $7^{\text {th }}$ grades

\begin{tabular}{|c|c|c|c|c|c|}
\hline BMI changes child & $\begin{array}{l}\text { Total } \\
n=427(\%)\end{array}$ & $\begin{array}{l}\text { Change in } \\
\text { 'Junk/convenient' } \\
\text { Beta }(95 \% \mathrm{Cl})\end{array}$ & $\begin{array}{l}\text { Change in } \\
\text { 'Varied Norwegian' } \\
\text { Beta }(95 \% \mathrm{Cl})\end{array}$ & $\begin{array}{l}\text { Change in } \\
\text { 'Snacking' } \\
\text { Beta }(95 \% \mathrm{Cl})\end{array}$ & $\begin{array}{l}\text { Change in } \\
\text { 'Dieting' } \\
\text { Beta }(95 \% \mathrm{Cl})\end{array}$ \\
\hline Unchanged normal weight & $345(81)$ & Reference & Reference & Reference & Reference \\
\hline Overweight/obese to normal weight & $20(5)$ & $-0.07(-0.44,0.31)$ & $-0.04(-0.43,0.35)$ & $0.14(-0.31,0.58)$ & $-0.04(-0.45,0.37)$ \\
\hline Normal weight to overweight/obese & $21(5)$ & $-0.15(-0.50,0.19)$ & $-0.07(-0.43,0.29)$ & $-0.24(-0.65,0.16)$ & $0.13(-0.25,0.51)$ \\
\hline Unchanged overweight/obesity & $41(10)$ & $-0.11(-0.39,0.17)$ & $-0.28(-0.57,0.01)$ & $-0.03(-0.37,0.30)$ & $0.21(-0.10,0.52)$ \\
\hline
\end{tabular}

$\S$ Beta coefficients (beta) and $95 \%$ confidence intervals (95\% Cl). All models were adjusted for the other pattern scores and significantly associated background variables.

Table 5 Changes in eating pattern scores and risk ${ }^{\S}$ of remaining overweight between the $4^{\text {th }}$ and $7^{\text {th }}$ grades $(\mathrm{n}=386$ )

\begin{tabular}{|c|c|c|c|c|}
\hline Eating pattern change & $\mathbf{n}$ & $\begin{array}{l}\text { Unchanged overweight } \\
\text { n (\%) }\end{array}$ & OR crude $^{1}(95 \% \mathrm{Cl})$ & OR adjusted $^{2}(95 \% \mathrm{Cl})$ \\
\hline \multicolumn{5}{|l|}{ 'Junk/convenient' } \\
\hline Decreased scores & 201 & $26(13)$ & 1 & 1 \\
\hline Stable or increased scores & 185 & $15(8)$ & $0.7(0.3,1.3)$ & $0.8(0.4,1.7)$ \\
\hline \multicolumn{5}{|l|}{ 'Varied Norwegian' } \\
\hline Decreased scores & 172 & $27(16)$ & 1 & 1 \\
\hline Stable or increased scores & 214 & $14(7)$ & $0.4(0.2,0.8)$ & $0.4(0.2,0.8)$ \\
\hline \multicolumn{5}{|l|}{ 'Snacking' } \\
\hline Decreased scores & 169 & $16(9)$ & 1 & 1 \\
\hline Stable or increased scores & 217 & $25(12)$ & $1.2(0.6,2.4)$ & $1.4(0.7,2.9)$ \\
\hline \multicolumn{5}{|l|}{ 'Dieting' } \\
\hline Decreased & 174 & $16(9)$ & 1 & 1 \\
\hline Stable or increased scores & 212 & $25(12)$ & $1.3(0.6,2.5)$ & $1.3(0.6,2.7)$ \\
\hline
\end{tabular}

$\S$ Odds ratio (OR) and $95 \%$ confidence intervals $(95 \% \mathrm{Cl})$.

${ }^{1}$ Adjusted for the other eating patterns.

${ }^{2}$ Adjusted for the other eating patterns and significantly associated background variables. 
increased risk of overweight for children with high scores for eating patterns characterised by the frequent intake of unhealthy food items.

Tracking was observed for all eating patterns between the two time points. Strong correlation coefficients were observed between factor scores for similar patterns at the two time points, suggesting reasonable stability in individual eating habits over the time period studied. However, significant inverse correlations were observed between two of the $4^{\text {th }}$-grade patterns and "varied Norwegian" in the $7^{\text {th }}$ grade, possibly indicating that children with high $4^{\text {th }}$-grade scores for the "snacking" or "dieting" patterns had lower $7^{\text {th }}$-grade scores for the "varied Norwegian" pattern, and consequently less frequent consumption of the food items included in the dietary guidelines. Likewise, the positive correlation between the "varied Norwegian" pattern in the $4^{\text {th }}$ grade and the "dieting" pattern in the $7^{\text {th }}$ grade could indicate a shift toward more frequent use of fat- and sugar-reduced food and drink items (light products) by many children over the time studied. The weighted $\kappa$-values confirmed moderate individual tracking [31] of the "junk/convenient", "varied Norwegian" and "dieting" patterns, and fair tracking of the "snacking" pattern, during the three-year follow-up period. A combination of stability and changes in eating patterns of children and adolescents has also been reported in previous studies $[4,6,14,15,32]$. The present study supports the proposition that eating habits are tracked from middle childhood into early adolescence, but also emphasise the important changes in children's food habits that occur during this particular period of life.

The correlation between BMI measurements at the two time points was high. In the follow-up sample, the majority of children were still of normal weight $(80 \%), 5 \%$ of the children moved from overweight to normal weight, $5 \%$ moved from normal weight to overweight and 10\% remained overweight. A number of studies have investigated BMI tracking during childhood and adolescence $[33,34]$ and from childhood and adolescence into adulthood $[35,36]$. The results consistently show a high degree of tracking from childhood to adolescence, a finding supported by the present study.

An important finding in the present study was that children with a high adherence to the 'varied Norwegian' pattern in the $7^{\text {th }}$ grade were less likely to be overweight than children with a low adherence to this pattern, and that children with no change or a positive change in this pattern over time were less likely to remain overweight. It is of particular interest to note that while high scores for the "varied Norwegian" eating pattern were associated with an increased risk of overweight in the $4^{\text {th }}$ grade [3], high scores for the same pattern in the $7^{\text {th }}$ grade were associated with a decreased risk. This change in direction may partly be explained by the changes observed in the composition of the "varied Norwegian" pattern over time, but it is more likely to be explained by individual changes in eating habits by age. Our results showed lower intake of vegetables and less regular breakfast eating among overweight compared to normal weight children at the $7^{\text {th }}$ grade stage. A decreased intake of vegetables and more irregular meal patterns by age have been observed in a nationwide study of Norwegian adolescents [37]. In our study, this trend was only observed among overweight children. The positive association between the "varied Norwegian" pattern and BMI status was evident independent of parental characteristics, gender and physical activity of the child, and corroborates current dietary guidelines which recommend eating a variety of foods including vegetables, fruit, unrefined cereal products and fish and having regular main meals. Regular meals and, especially, regular breakfast intake, have been associated with a reduced risk of overweight in several studies [7,38-42]. A study of food and activity patterns in a longitudinal study of Greek children confirmed that eating frequency, breakfast consumption and adherence to a healthy diet characterised as Mediterranean were negatively associated with overweight [7]. In a study of Norwegian adolescents, in which Telemark was one of two participating counties, eating four (rather than fewer) meals per day was significantly negatively related to being overweight [40].

It has been difficult to demonstrate an increased risk of overweight and obesity for children with a high adherence to unhealthy dietary patterns $[5,8,19,23]$. However, the British ALSPAC study reported a positive relationship between high-energy diets at ages five and seven and overweight at age nine [24]. In the European DONALD study [25], a small but positive association between consumption of high-energy convenience foods and bodyweight was found among boys. In the present study, we were unable to demonstrate any significant associations with overweight for the eating patterns characterised by frequent intake of unhealthy food items through either cross-sectional or longitudinal data analyses. This may be due to misreporting, including over-reporting of healthy food items and/or under-reporting of unhealthy food items. It is known that food and drink items perceived as 'unhealthy' are under-reported more often than other foods, especially if the children are overweight [43-45]. Another explanation could be that 12- to 13-year-old children eat unhealthy food items when their parents are not aware of it. On the other hand, children that are lean and physically active may tolerate a higher intake of highenergy foods, and are not as likely to under-report these items. Any misreporting is likely to have attenuated the association between eating behaviour and overweight.

Dieting behaviour has been associated with overweight in adolescence $[46,47]$. In the present study, children 
with high adherence to a "dieting" pattern were more likely to be overweight than those with low adherence to this pattern in $7^{\text {th }}$ grade as well as in $4^{\text {th }}$ grade. Many so-called "light" products or typical dieting products are intended as substitutes for food items with a high fat or sugar content. Our results did not show any benefit with regard to weight reduction in children having stable or increased scores on the dieting pattern over time. Rather than encouraging weight control mainly through the increased use of fat- and sugar-reduced food products, parents should strive to include more unrefined plant foods, fish, water, and regular meals in their family diet.

The objective measurement of the weight and height of the children at both time points is a major strength of the present study. Self-reported data have been shown to underestimate overweight prevalence in adolescents [48]. Other strengths of the present study include identical data collection at both time points and inclusion of a broad range of background variables, which are likely to capture a significant proportion of the variability in socioeconomic status and health behavior. The longitudinal design and the simultaneous assessment of BMI, diet and physical activity are important in order to evaluate the influence of dietary behavior and physical activity over time. However, our study also has limitations. A problem common to papers using PCA is that the factors are identified based on scree plots, eigenvalues and the interpretability of the components, which involves a good deal of subjectivity. This does not mean that it is not a good method, but the reader must be aware of these limitations. The FFQ did not include portion sizes, and calculating energy and nutrient intakes was not feasible. Consequently, we could not evaluate the validity of the reported intakes based on total energy intake. However, the reproducibility and validity of PCA-derived dietary patterns assessed using FFQs have previously been found to be satisfactory [49]. The FFQ was completed by the parents, and it is likely that the dietary data reflect the parents' "dietary image" rather than the true habitual diet of the children [50]. Parental reporting was chosen to avoid different data collection conditions at the two time points and to reduce underreporting, which is thought to be common in adolescents [51]. Even if the number of children participating at both time points was reasonably large, there was a loss to follow-up, which was mainly due to incomplete data. The incidence of overweight was lower in the $7^{\text {th }}$ grade than in the $4^{\text {th }}$ grade. The parents did not receive any feedback regarding the child's weight status after the $4^{\text {th }}$ grade study in order to reduce the risk of bias in how parents of overweight children reported the dietary behaviour in the follow-up study. However, we cannot exclude the possibility that the decrease in overweight could be due to underrepresentation of overweight and obese children in the follow-up study, especially among girls. Greater focus on body image and weight control [51] in adolescence may be a reason for lower participation by overweight girls in the $7^{\text {th }}$ grade.

To provide a better understanding of the longitudinal relationship between diet and overweight in adolescents, additional research is needed. We intend to repeat the study when the children reach the age of 15 to 16 years.

\section{Conclusions}

We observed slight to moderate stability of eating patterns between middle childhood and early adolescence, but important changes in individual eating habits were also observed. Children adhering to a "varied Norwegian" eating pattern over time were less likely to remain overweight than children with declining adherence to this pattern. The association was evident independent of parental characteristics, gender and the physical activity levels of the children. Our results indicate that in order to reach normal weight, overweight children should be encouraged to eat regular main meals and retain a diverse diet including unrefined plant foods, water and fish, rather than fat- and sugar-reduced foods and drinks.

\section{Abbreviations}

BMI: Body Mass Index; FFQ: Food Frequency Questionnaire; PCA: Principal Component Analysis; IOTF: International Obesity Task Force; Cl: Confidence intervals.

\section{Acknowledgements}

This research was supported by Telemark University College, Telemark Hospital, the Research Council of Norway, and the Public Health Programme for Telemark

The authors appreciate the cooperation of the children and their parents, the faculty and staff of the Telemark County primary and lower secondary schools, and the public health nurses that participated in this study.

\section{Author details}

Faculty of Health and Social Sciences, Department of Health Studies, Telemark University College, Porsgrunn, Norway. ${ }^{2}$ Department of Occupational and Environmental Medicine, Telemark Hospital, Skien, Norway. ${ }^{3}$ Norwegian Institute of Public Health, Division of Environmental Medicine, Oslo, Norway.

\section{Authors' contributions}

IMO and MVS were responsible for the study design and data collection. MVS was responsible for the statistical analyses. ALB and IMO assisted in the statistical analyses, and ALB contributed to the interpretation of results. IMO drafted the manuscript. All authors read and approved the final manuscript.

\section{Competing interests}

The authors declare that they have no competing interests.

Received: 8 June 2011 Accepted: 6 October 2011

Published: 6 October 2011

\section{References}

1. Aranceta J, Perez-Rodrigo C, Ribas L, Serra-Majem L: Sociodemographic and lifestyle determinants of food patterns in Spanish children and adolescents: the enKid study. Eur J Clin Nutr 2003, 57:S40-S44. 
2. Roos EB, Karvonen S, Rahkonen O: Lifestyles, social background and eating patterns of 15-year old boys and girls in Finland. Journal of Youth Studies 2004, 7:331-349.

3. Oellingrath $\mathrm{IM}$, Svendsen MV, Brantsæter AL: Eating patterns and overweight in 9- to 10-year-old children in Telemark County, Norway: a cross-sectional study. Eur J Clin Nutr 2010.

4. Mikkila V, Rasanen L, Raitakari OT, Pietinen P, Viikari J: Consistent dietary patterns identified from childhood to adulthood: The cardiovascular risk in young finns study. British Journal of Nutrition 2005, 93(6):923-931.

5. Moreira P, Santos S, Padrao P, Cordeiro T, Bessa M, Valente H, Barros R, Teixeira V, Mitchell V, Lopes C, et al: Food patterns according to sociodemographics, physical activity, sleeping and obesity in Portuguese children. Int J Environ Res Public Health 2010, 7(3):1121-1138.

6. Patterson E, Warnberg J, Kearney J, Sjöström M: The tracking of dietary intakes of children and adolescents in Sweden over six years: the European Youth Heart Study. International Journal of Behavioral Nutrition and Physical Activity 2009, 6(1):91

7. Kontogianni MD, Farmaki AE, Vidra N, Sofrona S, Magkanari F, Yannakoulia M: Associations between Lifestyle Patterns and Body Mass Index in a Sample of Greek Children and Adolescents. Journal of the American Dietetic Association 2010, 110(2):215-221.

8. Craig LC, McNeill G, Macdiarmid Jl, Masson LF, Holmes BA: Dietary patterns of school-age children in Scotland: association with socio-economic indicators, physical activity and obesity. Br J Nutr 2010, 103(3):319-334.

9. Northstone K, Emmett P: Multivariate analysis of diet in children at four and seven years of age and associations with socio-demographic characteristics. Eur J Clin Nutr 2005, 59:751-760.

10. Jacques PF, Tucker KL: Are dietary patterns useful for understanding the role of diet in chronic disease? Am J Clin Nutr 2001, 73:1-2.

11. Hu FB: Dietary pattern analysis: a new direction in nutritional epidemiology. Curr Opin Lipidol 2002, 13:3-9.

12. Newby PK, Tucker KL: Empirically derived eating patterns using factor or cluster analysis: A review. Nutrition Reviews 2004, 62(5):177-203.

13. Twisk JWR: Applied longitudinal data analysis for epidemiology: a practical guide. Cambridge: Cambridge University Press; 2007.

14. Wang YF, Bentley ME, Zhai FY, Popkin BM: Tracking of dietary intake patterns of Chinese from childhood to adolescence over a six-year follow-up period. Journal of Nutrition 2002, 132(3):430-438

15. Northstone K, Emmett PM: Are dietary patterns stable throughout early and mid-childhood? A birth cohort study. Br J Nutr 2008, 100:1069-1076.

16. Lytle LA, Seifert S, Greenstein J, McGovern P: How do children's eating patterns and food choices change over time? Results from a cohort study. American Journal of Health Promotion 2000, 14(4):222-228.

17. Demory-Luce D, Morales M, Nicklas T, Baranowski T, Zakeri I, Berenson G: Changes in food group consumption patterns from childhood to young adulthood: The Bogalusa Heart Study. Journal of the American Dietetic Association 2004, 104(11):1684-1691.

18. Andersen LF, Lillegaard IT, Øverby NC, Lytle L, Klepp Kl, Johansson L: Overweight and obesity among Norwegian schoolchildren: changes from 1993 to 2000. Scand J Public Health 2005, 33:99-106

19. Alexy U, Sichert-Hellert W, Kersting M, Schultze-Pawlitschko V: Pattern of long-term fat intake and BMI during childhood and adolescence[mdash] results of the DONALD Study. Int J Obes Relat Metab Disord 2004, 28:1203-1209.

20. Reilly JJ, Armstrong J, Dorosty AR, Emmett PM, Ness A, Rogers I: Early life risk factors for obesity in childhood: cohort study. BMJ 2005, 330:1357.

21. Ludwig DS, Peterson KE, Gortmaker SL: Relation between consumption of sugar-sweetened drinks and childhood obesity: a prospective, observational analysis. Lancet 2001, 357:505-508.

22. Nicklas TA, Yang SJ, Baranowski T, Zakeri I, Berenson G: Eating patterns and obesity in children. The Bogalusa Heart Study. Am J Prev Med 2003, 25:9-16

23. Newby PK: Are dietary intakes and eating behaviors related to childhood obesity? A comprehensive review of the evidence. J Law Med Ethics 2007, 35:35-60.

24. Johnson L, Mander AP, Jones LR, Emmett PM, Jebb SA: Energy-dense, lowfiber, high-fat dietary pattern is associated with increased fatness in childhood. Am J Clin Nutr $2008,87: 846-854$

25. Alexy U, Libuda L, Mersmann S, Kersting M: Convenience foods in children's diet and association with dietary quality and body weight status. Eur J Clin Nutr 2011, 65(2):160-166
26. Janz KF, Broffitt B, Levy SM: Validation evidence for the Netherlands physical activity questionnaire for young children: the lowa bone development study. Res Q Exerc Sport 2005, 76:363-369.

27. Cole TJ, Flegal KM, Nicholls D, Jackson AA: Body mass index cut offs to define thinness in children and adolescents: international survey. BM 2007, 335:194

28. Cole TJ, Bellizzi MC, Flegal KM, Dietz WH: Establishing a standard definition for child overweight and obesity worldwide: international survey. BMJ 2000, 320:1240-1243.

29. Cattell RB: The scree test for the number of factors. Multivariate Behavioral Research 1966, 1:245-276.

30. Cohen J: Weighted kappa - Nominal scale agreement with provision for scaled disagreement or partial credit. Psychological Bulletin 1968, 70(4):213-\&.

31. Landis JR, Koch GG: Measurement of observer agreement for categorical data. Biometrics 1977, 33(1):159-174.

32. Cutler GJ, Flood A, Hannan P, Neumark-Sztainer D: Major Patterns of Dietary Intake in Adolescents and Their Stability over Time. Journal of Nutrition 2009, 139(2):323-328.

33. Wang Y, Ge K, Popkin BM: Tracking of body mass index from childhood to adolescence: a 6-y follow-up study in China. Am J Clin Nutr 2000 72(4):1018-1024

34. Julia M, van Weissenbruch MM, Prawirohartono EP, Surjono A, Delemarrevan de Waal HA: Tracking for underweight, overweight and obesity from childhood to adolescence: a 5-year follow-up study in urban Indonesian children. Horm Res 2008, 69(5):301-306.

35. Kvaavik E, Tell GS, Klepp K-I: Predictors and Tracking of Body Mass Index From Adolescence Into Adulthood: Follow-up of 18 to 20 Years in the Oslo Youth Study. Arch Pediatr Adolesc Med 2003, 157(12):1212-1218.

36. Williams S, Davie G, Lam F: Predicting BMI in young adults from childhood data using two approaches to modelling adiposity rebound. Int J Obes Relat Metab Disord 1999, 23(4):348-354.

37. Samdal O, Leversen I, Torsheim T, Manger MS, Brunborg GS, Wold B: Trender i helse og livsstil blant barn og unge 1985-2005. Norske resultater fra studien "Helsevaner blant skoleelever. En WHO undersøkelse i flere land". The Health Behaviour in School-Aged Children: WHO Collaborative Cross-National Study (HBSC). In Norwegian. Bergen: Research Centre for Health Promotion, The University of Bergen; 2009:2009:3

38. Hania S, Marek R: Systematic Review Demonstrating that Breakfast Consumption Influences Body Weight Outcomes in Children and Adolescents in Europe. Critical Reviews in Food Science and Nutrition 2010, 50(2):113-119.

39. Berthold K, Andre Michael T: Meal Patterns and Frequencies: Do They Affect Body Weight in Children and Adolescents? Critical Reviews in Food Science and Nutrition 2010, 50(2):100-105.

40. Vik FN, Øverby NC, Lien N, Bere E: Number of meals eaten in relation to weight status among Norwegian adolescents. Scandinavian Journal of Public Health 2010, 38:13-18.

41. Sjöberg A, Hallberg L, Höglund D, Hulthén L: Meal pattern, food choice, nutrient intake and lifestyle factors in The Goteborg Adolescence Study. Eur J Clin Nutr 2003, 57:1569-1578.

42. Lehto R, Ray C, Lahti-Koski M, Roos E: Meal pattern and BMI in 9-11-yearold children in Finland. Public Health Nutrition 2010, FirstView: 1-6.

43. Vance VA, Woodruff SJ, McCargar LJ, Husted J, Hanning RM: Self-reported dietary energy intake of normal weight, overweight and obese adolescents. Public Health Nutr 2009, 12:222-227.

44. Johansson L, Solvoll K, Bjørneboe GE, Drevon CA: Under- and overreporting of energy intake related to weight status and lifestyle in a nationwide sample. Am J Clin Nutr 1998, 68:266-274.

45. Olafsdottir AS, Thorsdottir I, Gunnarsdottir I, Thorgeirsdottir $H$ Steingrimsdottir L: Comparison of women's diet assessed by FFQs and 24-h recalls with and without underreporters: associations with biomarkers. Ann Nutr Metab 2006, 50:450-460

46. Neumark-Sztainer D, Wall M, Haines J, Story M, Eisenberg ME: Why Does Dieting Predict Weight Gain in Adolescents? Findings from Project EATII: A 5-Year Longitudinal Study. Journal of the American Dietetic Association 2007, 107(3):448-455.

47. Field AE, Austin SB, Taylor CB, Malspeis S, Rosner B, Rockett HR, Gillman MW, Colditz GA: Relation between dieting and weight change among preadolescents and adolescents. Pediatrics 2003, 112(4):900-906. 
48. Sherry B, Jefferds ME, Grummer-Strawn LM: Accuracy of adolescent selfreport of height and weight in assessing overweight status: a literature review. Arch Pediatr Adolesc Med 2007, 161(12):1154-1161.

49. Hu FB, Rimm E, Smith-Warner SA, Feskanich D, Stampfer MJ, Ascherio A, Sampson L, Willett WC: Reproducibility and validity of dietary patterns assessed with a food-frequency questionnaire. American Journal of Clinical Nutrition 1999, 69(2):243-249.

50. Drewnowski A: Diet image: a new perspective on the food-frequency questionnaire. Nutr Rev 2001, 59:370-372.

51. Livingstone $\mathrm{MB}$, Robson PJ: Measurement of dietary intake in children. Proc Nutr Soc 2000, 59:279-293.

doi:10.1186/1475-2891-10-106

Cite this article as: Oellingrath et al.: Tracking of eating patterns and overweight - a follow-up study of Norwegian schoolchildren from middle childhood to early adolescence. Nutrition Journal 2011 10:106.

\section{Submit your next manuscript to BioMed Central} and take full advantage of:

- Convenient online submission

- Thorough peer review

- No space constraints or color figure charges

- Immediate publication on acceptance

- Inclusion in PubMed, CAS, Scopus and Google Scholar

- Research which is freely available for redistribution

Submit your manuscript at www.biomedcentral.com/submit 